Agricultural Meteorology, 18(1.977) 1.63-186

(C) Elsevie: Scientific Publishing Company, Amsterdam - Printed in. The Netherlands

\title{
EXPERIMENTAL EVALUATION OF A CROP CLIMATE SIMULATION MODEL FOR INDIAN CORN (ZEA MAYS L.)
}

\author{
C. J. STIGTER *1 , J. GOUDRIAAN* ${ }^{2}$, F. A. BOTTEMANNE*1 ${ }^{1}$, J. BIRNIE*1, \\ J. G. LENGKEEK ${ }^{*}$ and L. SIBMA**3 \\ ${ }^{*}$ Department of Physics and Meteorology; $*^{2}$ Department of Theoretical Production \\ Ecology, Agricultural University, Wageningen (The Netherlands) \\ $*^{3}$ Centre for Agrobiological Research, Wageningen (The Netherlands)
}

(Received August 14, 1976; accepted January 27, 1977)

\section{ABSTRACT}

Stigter, C. J., Goudriaan, J., Bottemanne, F. A., Birnie, J., Lengkeek, J. G. and Sibma, L., 1977. Experimental evaluation of a crop climate simulation model for Indian corn (Zea mays L.). Agric. Meteorol., 18:163-186.

For the evaluation of a micrometeorological model, extensive measurements were taken of the microclimate in a maize crop. Both the model and the measurements are discussed in this paper. In a comparison of the measured and simulated characteristics of the microclimate it is concluded that the absorption of radiative energy and the leaf and boundary layer resistances are adequately simulated, so that this micrometeorological model presents a sound basis for simulation models of crop production. Profiles of aerial temperature and humidity are also reasonably simulated. They can still be improved upon by a better incorporation of spatial and temporal variations of turbulence and wind as a function of the canopy characteristics, and probably by a better simulation of exchange at the soil surface.

\section{INTRODUCTION}

In a recent editorial, Newman (1974) stated that "computer simulation of agricultural production systems will occupy a central place in agricultural technological development in the coming decades ... But, purely statistical or stochastic approaches should be replaced by more deterministic prediction methods as they are perfected through future research efforts".

Such deterministic methods, using quantitative mathematical relationships describing physical and chemical processes of importance in the biological behaviour of plants and animals, need much work to improve their reliability.

A submodel is necessary to estimate quantitatively the abiotical factors that influence the biological processes. Such a micrometeorological sub-

*Present address of C. J. Stigter: Department of Physics, University of Dar es Salaam, P. O. Box 35063, Dar es Salaam, Tanzania. 


\section{4}

model should preferably be able to simulate the aerial microclimate using characteristic geometrical, optical and physiological canopy properties and measurements of meteorological parameters above the crop (Goudriaan and Waggoner, 1972) or even at the nearest standard observational station. Measurements above the crop concerned have to be used until the difficulties of simulation from standard meteorological measurements are resolved.

In an evaluation of micrometeorological simulation models, specific input and check of output must be collected from the same experimental set up. Therefore, the experimental evaluation of the present model is concentrated on the use of measurements of as many different parameters as possible in one and the same corn field. Measurements were done on several measuring. days (in 1972 and 1973) chosen for their high and relatively undisturbed radiation values over the day.

\section{SIMULATION MODEL USED}

An early stage of the model used was described by Goudriaan and Waggoner (1972) and by Stigter (1972). Considerable changes were subsequently made in the model. An extensive up-to-date description is given by Goudriaan (1977). In the context of this paper no more than an outline of the model can be given, for which the scheme of Table I can be used.

\section{TABLE I}

Outline of the model

\begin{tabular}{lll}
\hline Input & Dynamic simulation & $\begin{array}{l}\text { Output (both current values } \\
\text { and daily totals or averages) }\end{array}$ \\
\hline $\begin{array}{l}\text { Meteorological parameters } \\
\text { above the canopy }\end{array}$ & $\begin{array}{l}\text { Radiation: long wave or } \\
\text { thermal, visible, near } \\
\text { infrared } \\
\text { Turbulence above canopy } \\
\text { and wind }\end{array}$ & $\begin{array}{l}\text { Total fluxes from vegeta- } \\
\text { tion and soil surface }\end{array}$ \\
Canopy characteristics & $\mathrm{CO}_{2}$ assimilation \\
& $\begin{array}{l}\text { Leaf assimilation and } \\
\text { transpiration }\end{array}$ & Profiles of air conditions \\
Balances at the soil surface & Profiles of dew \\
\hline
\end{tabular}

\section{INPUTS}

Since the total simulation period only extends over one or two days no allowance is made for growth. All characteristics and variables are assumed 
to be horizontally homogeneous (e.g., Stigter et al., 1976b; Stigter, 1976). The required above-canopy meteorological parameters are daily runs of air temperature, air humidity, wind speed, net radiation and/or incoming global radiation. The resolution in time need not be higher than half-hour averages. Both height of measurement (reference height) and height of the crop must be recorded. Other required crop characteristics are total leaf area index (and if possible its distribution with height), the leaf angle distribution, reflection and transmission coefficient of leaves in the visible and nearinfrared regions and also the dimensions of the leaves. There must be quantitative knowledge on the dependence of leaf resistance on external (environment) and internal (leaf) conditions.

Soil characteristics that must be known are thermal conductivity and heat capacity. The state of the soil surface is described by a characteristic length, such as the width of the clods, and by the moisture conditions. The model does not simulate the drying process of the soil surface, so that the moisture condition must be described by a resistance for evaporation analogous to leaf resistance. With a dry soil its value becomes very large and with a wet soil surface it is zero. When the initial temperature distribution inside the soil is not known, it can be approximated by the average daily air temperature over the whole depth of the soil. Then by one 24 -h run of the simulation model, using the proper daily courses of the input variables, a further approximation is obtained, which is accurate enough because the impact of the initial state of the soil temperatures appears to be small.

\section{DYNAMIC SIMULATION}

The simulation model is composed of a number of interacting submodels, among which only the salient features will be discussed.

\section{Radiation}

The purpose of the radiation submodel is to calculate the absorbed amounts of visible and of total radiative energy at different levels in the canopy and at the soil surface. To this end the radiation spectrum is roughly divided into three classes: the visible region from $0.4-0.7 \mu \mathrm{m}$ wavelength (VIS), the near-infrared region (NIR) from $0.7-2.0 \mu \mathrm{m}$ and the long-wave region (LWR) above $2 \mu \mathrm{m}$. For maize the reflection and transmission coefficients of the leaves are not greatly different, and because of the computational advantages they are assumed to be equal. Together they signify the scattering coefficient which is taken as $0.2,0.85$ and zero for the VIS, NIR and LWR regions, respectively (Gates et al., 1965; Ross, 1976); in particular for NIR, repeated scattering must be taken into account. From a separate radiation model a simple rule was derived for the extinction and reflection in the case of a high scattering coefficient (Goudriaan, 1977). 
Exponential extinction gives a fair approximation in most cases, both for separate wave bands and for total radiation.

To give an idea of the magnitude in maize, which has a practically isotropic leaf angle distribution (Ross, 1976); the average values for the extinction coefficient are 0.64 and 0.32 for cliffuse VIS and NIR. The profiles are not exactly exponential so that the numbers may still vary with depth up to 0.04 . The extinction coefficient for total global radiation is about 0.45 . For diffuse radiation, the reflection coefficients are about 0.05 and 0.35 for VIS and NIR, so that the reflection coefficient for total global radiation is about 0.20 .

For direct radiation, the extinction and reflection.coefficients generally decrease with the rising of the sun. At a solar height of about $40^{\circ}$ they equal the values for diffuse radiation.

Above the canopy the net LWR is usually negative. If leaves and soil surface are uniform in temperature, the net emitted LWR decreases approximately exponentially with leaf-area index. In general, however, the leaf temperatures are not uniform and are not equal to the soil surface temperature. Therefore, their emission of LWR is taken into account separately, which improves the net radiation profile considerably during night conditions. In daytime this improvement is quantitatively negligible with respect to the fluxes of global radiation.

\section{Turbulence and wind}

The windspeed at any level in the canopy is needed to compute the boundary-layer resistance of the leaves. The resistances for transport of heat, mass and momentum in the air between two levels $z_{1}$ and $z_{2}$ is found by integrating the inverse exchange coefficients $\left(\mathrm{m}^{2} \mathrm{~s}^{-1}\right)$ from level $z_{1}$ to level $z_{2}$.

Under neutral conditions a logarithmic wind profile exists up to some height above the canopy, if the latter is sufficiently uniform (Monteith, 1973). From the windspeed observed at reference height, the corresponding friction velocity $u_{*}$ and then the exchange coefficient for momentum can be calculated. The exchange coefficient for heat is 1.35 times larger (Businger et al., 1971). It is assumed that mass and heat are transported with equal efficiency.

Under non-neutral conditions some corrections must be applied; these are taken from Businger et al. (1971). These corrections lead to a complete inversion when Richardson's number $(R i)$ exceeds 0.21 , so that the exchange is practically nullified. Under unstable conditions ( $R i$ negative) the exchange coefficients are increased.

Inside the canopy an exponential decrease of windspeed can be derived, if it is assumed that a constant drag coefficient of the leaves exists (Den Hartog and Shaw, 1975), leaf density is homogeneous and the relative turbulence intensity is constant. Replacing the latter two assumptions by 
more realistic ones such as a parabolic leaf density distribution with height and a variable relative turbulence intensity (Shaw et al., 1974) yields a wind profile that is still very close to exponential (Goudriaan, 1977). The exchange coefficients are then found as the product of the mixing length which depends on the leaf area density, the windspeed and the relative turbulence intensity. Under non-neutral conditions they are corrected in the same way as above the canopy.

The resistances found in this manner are used to calculate the vertical fluxes of heat, moisture and $\mathrm{CO}_{2}$ as a function of height and time: Height is specified in relation to a small number of layers inside the canopy and it appeared that only 3 layers provided sufficient resolution in the profiles. The layers of air inside the canopy exchange heat and mass with the leaves that they contain and with the adjacent layers. These net fluxes are integrated with respect to time. A steady state is soon reached because of the small time constant of this process (about 100 seconds). When a matrix method is used, the steady state can be found directly (Waggoner et al., 1969), but for reasons of lucidity of the simulation program the integration method was preferred. Some problems with the numerical integration, due to the small time constant (stiffness), are further discussed by Goudriaan, 1977.

\section{Leaf assimilation and transpiration}

The boundary layer resistance is related to the windspeed and the width of the leaves according to a review of literature data by Pearman et al. (1972).

The leaf resistance $r_{\ell}$ depends on the rate of net $\mathrm{CO}_{2}$-assimilation, in such a way that the $\mathrm{CO}_{2}$-concentration in the stomatal cavity is regulated at about $120 \mathrm{vpm}$ (maize) (Goudriaan and Van Laar, 1977). This relation can be used for modelling purposes. Within a layer the leaf surfaces are classified according to their irradiation. The fractions of shaded and sunlit leaves, and their inclination distribution with respect to the direct solar radiation, are calculated in the radiation submodel. The rate of net $\mathrm{CO}_{2}$ assimilation in each of the instances is found from the absorbed visible radiation and the plant properties describing the net photosynthesis-light response curve (Van Laar and Penning de Vries, 1972).

The maximum $\mathrm{CO}_{2}$-assimilation $P_{\mathrm{m}}$ and the dark respiration $R_{\mathrm{d}}$ are both functions of temperature. At low temperatures leaf assimilation is reduced, and so also is the stomatal aperture.

The leaf transpiration rate is expressed by a modified Penman equation (Monteith, 1973), which uses the leaf resistance $\left(r_{\ell}\right)$ and boundary layer resistance $\left(r_{\mathrm{b}}\right)$, the temperature and humidity of the air at the height of the leaf, and the total absorbed radiation per leaf area. The energy balance of the leaf surface also determines the heat loss and temperature of the leaf. 
168

Soil surface

The energy balance of the soil surface can be written in the same way as for a leaf surface. The boundary layer resistance is derived from a characteristic clod size and a windspeed extrapolated to the soil surface. Van Keulen (1975) presents a method to allow for the drying of the soil surface. His results indicate that a sharp transition in soil evaporation rate occurs from potential to a very low value at a moisture content of the top layer even below wilting point. This justifies the use of an evaporation resistance analogous to leaf resistance, which is either zero in most cases, or very large when the soil surface is dry. Compared to a leaf surface, the energy balance of the soil surface contains one additional term, the soil heat flux. This extra term complicates the energy balance, but it is still possible to derive a modified Penman equation, which finally yields the surface temperature $T_{\mathrm{s}}$ and the fluxes of evaporation, heat loss to the air and heat storage in the soil $(G)$. This soil heat flux $G$ can be considered as the driving force of the heat-flow regime in the soil underneath. The temperature profile of the soil is found by a division of the depth into compartments and integration with respect to time of the heat content of each compartment separately. This method is described in more detail by De Wit and Van Keulen (1972).

\section{MEASURING EQUIPMENT USED}

Descriptions in detail have been given of the 5 ha (1972) and 10 ha (1973) measuring fields and of the data logging and scanning equipment modifications used (Stigter et al., 1976b; Stigter et al., 1976a). It is of importance here to know that the planting pattern chosen for a first model evaluation was almost uniform with a row distance of $40 \mathrm{~cm}$ and three plants in $1 \mathrm{~m}$ within the row. Within the soil and crop environment 100 platinum-resistance temperature measuring points and 50 thermocouple outputs (psychrometers, air-novement meters) could be scanned, distributed as given in Table II.

Special attention has been given to a preliminary investigation throughout the canopy on the possible influence of high Fourier components on the averages of the sampled fluctuating signals of temperature, water vapour concentration and omnidirectional air movement. The scanning rate may corrupt the measured output with such Fourier components and this and other effects may influence the true means to be measured (e.g., Byrne, 1970, 1972; Fuchs, 1972; Stigter et al., 1976a). Results indicated that the scanning rates chosen added only minor errors in the determination of these true means. The worst cases of these errors have been assessed elsewhere (Stigter et al., 1976).

Regarding temperature measurements, which were also described in detail elsewhere, special attention was paid to a first assessment of horizontal homogeneity in the corn crop (Stigter et al., 1976b). Sensors were 
TABLE II

Distribution of sensors with height above or below the soil surface in a corn crop of about $2.50 \mathrm{~m}$. Together with two "zero" controls and 1.0 channels held in reserve for special measurements and urgent repairs, 150 channels are utilized.

\begin{tabular}{llll}
\hline $\begin{array}{l}\text { Height } \\
(\mathrm{m})\end{array}$ & Thermometers & Psychrometers & Anemometers \\
\hline 4.50 & 3 & - & - \\
4.00 & 3 & - & - \\
3.50 & 5 & 3 & 1 \\
3.00 & 5 & 3 & -1 \\
2.50 & 5 & 2 & 1 \\
2.10 & 5 & 3 & 2 \\
1.80 & 5 & 2 & 1 \\
1.50 & 5 & 3 & 2 \\
1.20 & 5 & 2 & 1 \\
0.90 & 5 & 4 & 2 \\
0.60 & 7 & 4 & 2 \\
0.30 & 9 & 2 & 1 \\
0.10 & 4 & 2 & 1 \\
0.05 & 4 & - & - \\
0.02 & 4 & - & - \\
-0.02 & 5 & - & - \\
-0.05 & 5 & - & 1 \\
-0.10 & 5 & 5 & \\
\hline
\end{tabular}

small platinum-resistance thermometers of a type comparable to those described by Long (1968) with specially constructed radiation shields in the above-soil measurements (Stigter et al., 1976b). Soil heat flow was sampled with heat-flow meters of the Delft Technical Physical Service (The Netherlands).

The measurement of water-vapour pressure was made by improved thermocouple psychrometers (Stigter and Welgraven, 1976; Stigter, 1976). Measurements of omnidirectional air movement inside and just above the canopy were made with adapted heated-sphere thermocouple anemometers (Stigter et al., 1976a). Both types of instruments were protected from possibilities of asymmetrical radiation influence on the junctions concerned (Fig.1).

Wind profiles and temperature difference measurements above the crop up to a height of nearly $6 \mathrm{~m}$ were made with adapted cup anemometers and thermocouples respectively so that values could be obtained of friction velocity, roughness height, displacement height and Richardson number (Bottemanne and Reitsma, 1973). Measuring sites could be chosen such that they had enough fetch for a good build-up of new wind profiles (Bottemanne and Reitsma, 1973) as well as temperature and humidity profiles (Stigter et al., 1976b; Stigter, 1976) along the prevailing wind directions on the measuring days. Special and scrupulous care was taken not to disturb the 


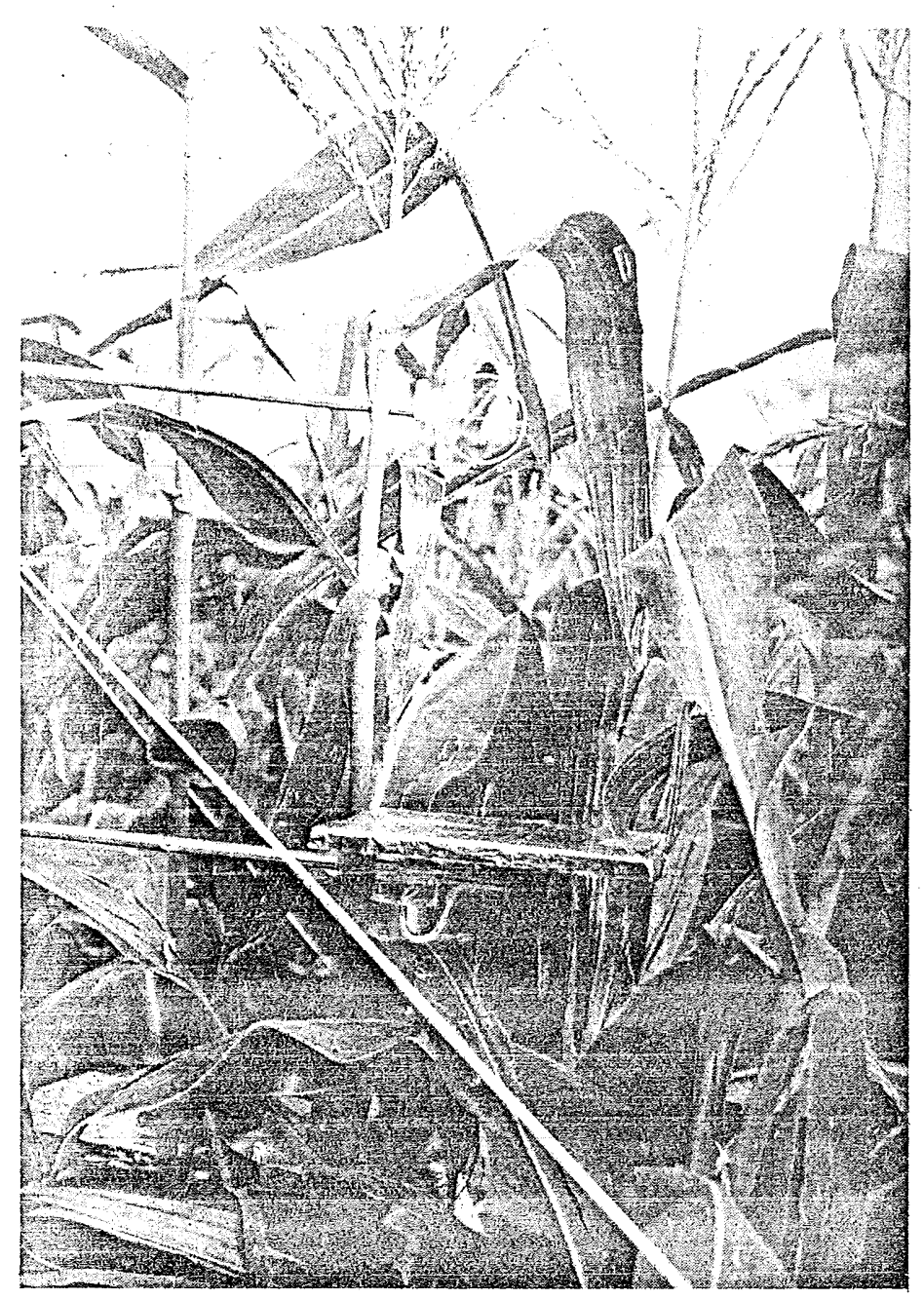

Fig.1. Psychrometer (below) and anemometer within the corn crop. Radiation fluxes are prevented from influencing the two junctions differently by a mylar on tempex foam radiation screen, supported on an aluminium base (psychrometer) and a coating of white paint of exceptionally high reflectance (anemometer). (Photograph J. v.d. Brink).

measuring environments, and measuring places could only be approached from a side opposite to these prevailing wind directions.

A parameter that was found from the beginning to be of paramount importance, in accordance with independent experience (e.g., Monteith, 1973; Kanemasu, 1975), was the leaf epidermal resistance (Stigter, 1972, 1974), and resulted in the construction of an improved leaf-diffusion meter (or porometer) that was thoroughly tested (Stigter et al., 1973) and used (Stigter and Lammers, 1974). The improved calibration method, which can also be used on commercially available porometers (Stigter and 
Visscher, 1975), and a special crop sampling system, made it possible to obtain most accurate leaf resistance profiles (Stigter and Lammers, 1974).

Net radiation above the crop was measured with a Funk net radiometer. Net radiation inside the crop, at the height of about $1 \mathrm{~m}$, was sampled with four independent mobile net radiometers mounted on an arm. Radiometers and equipment to move each of them over a path of $1 \mathrm{~m}$ were specially constructed for this purpose (Fig.2).

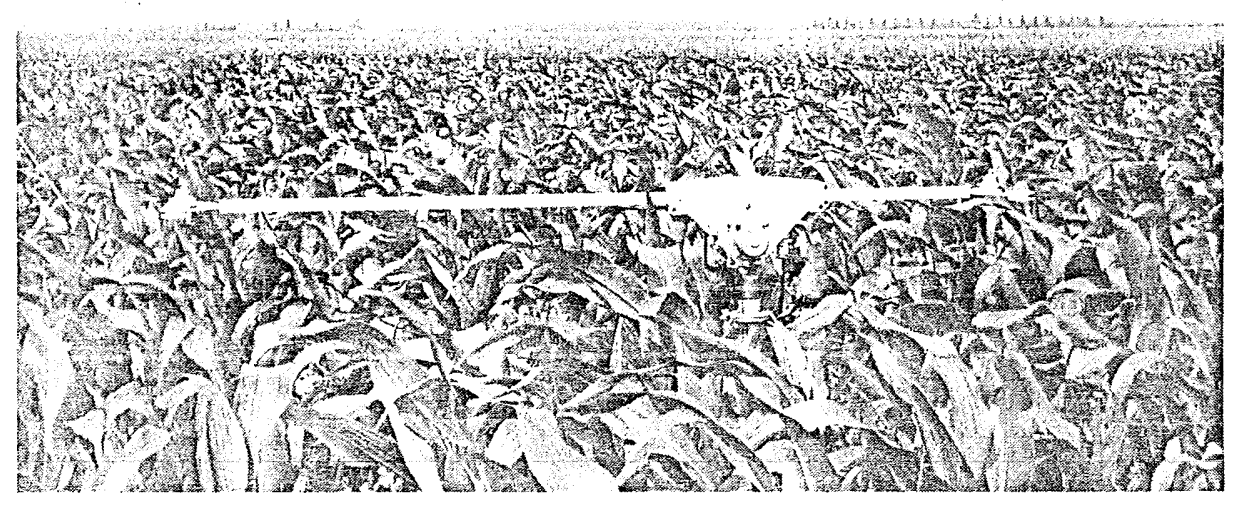

Fig. 2. Moving net radiometers shown over corn of somewhat less than $1 \mathrm{~m}$ height at the flat Flevoland experimental field (Photograph C. J. Stigter).

Leaf-area index and leaf-area distribution were measured by periodical stratified sampling of $25 \mathrm{~cm}$ - crop layers throughout specially outlined plots and determination of total leaf surface was obtained from these layers by use of a Diichi Boeki Shokai automatic area meter (AAMS).

\section{COMPARISON OF MEASURED AND SIMULATED OUTPUT VALUES}

Three days were chosen for the comparison, August 31, 1972, August 14, 1973 and August 23, 1973. The measured meteorological characteristics of these days are given in Fig. 3; all days were rather windy. The net radiation fluctuated a little on August 31, 1972, but the two days in 1973 were perfectly clear. Especially on the 14th of August 1973 the air was hot and dry, with a vapour pressure deficit rising to 20 mbar towards the end of the afternoon. 
172
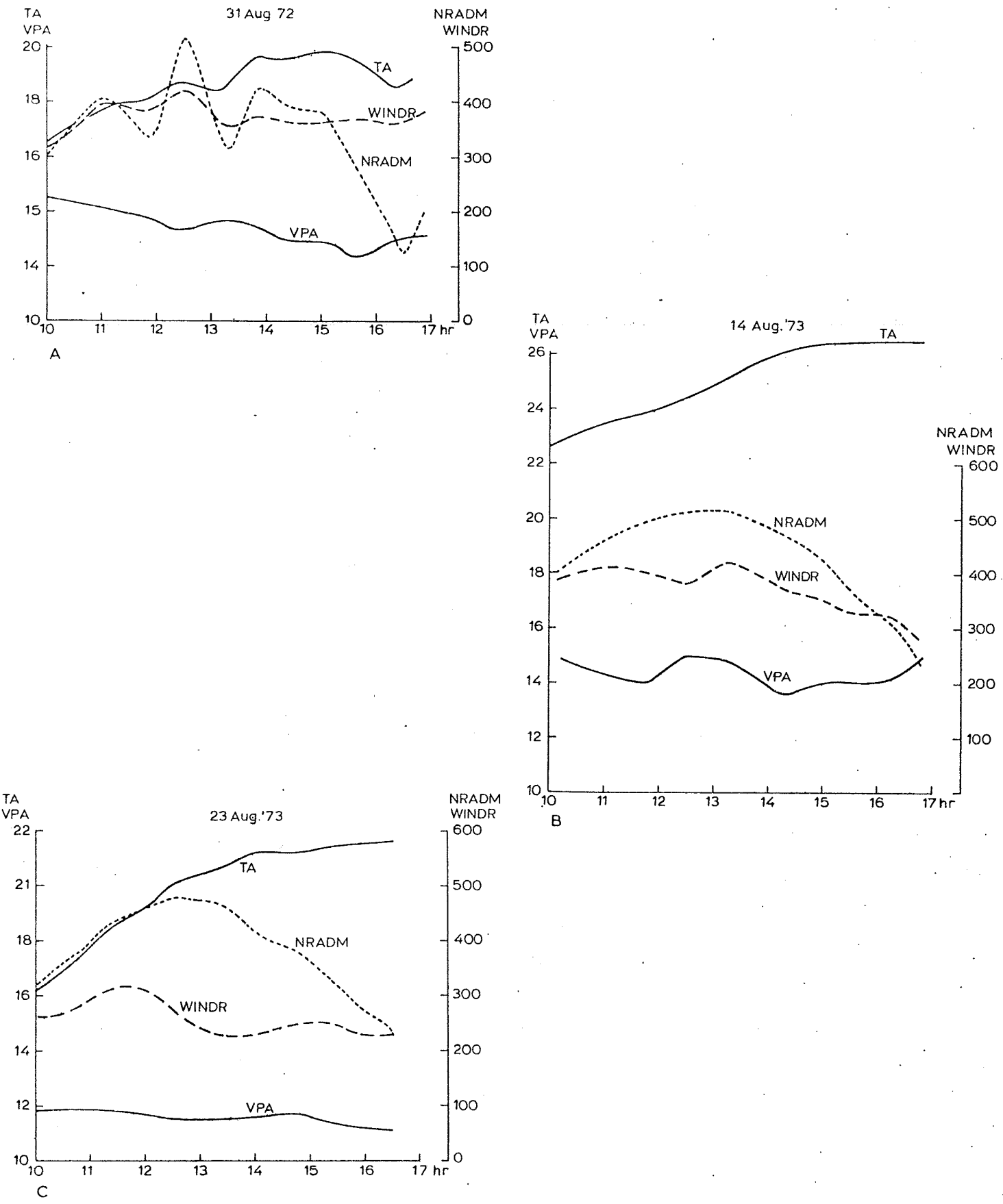

Fig. 3. Measured course of some meteorological characteristics at $3 \mathrm{~m}$ height above the soil on August 31, 1972 (A), August 14, 1973 (B) and August 23, 1973 (C). TA = air temperature (left ordinate) $\left({ }^{\circ} \mathrm{C}\right) ; V P A=$ air humidity (left ordinate) (mbar); WINDR $=$ wind speed (right ordinate) $\left(\mathrm{cm} \mathrm{s}^{-1}\right) ; N R A D M=$ net radiation (right ordinate) $\left(\mathrm{J} \mathrm{m}^{-2} \mathrm{~s}^{-1}\right)$. 


\section{Extinction of net radiation}

The net radiation, measured and simulated at a height of $0.95 \mathrm{~m}$ is given as a fraction of that above the canopy in Fig.4 for August 31, 1972 and August 14, 1973; both measured and simulated fractions are given as a function of time. The simulated fraction exhibits a slight maximum around noon and declines as the sun gets lower. The measured fraction shows peaks and dips which may partially be ascribed to crop inhomogeneities, but on the whole the simulated fraction gives a satisfactory representation of the measured fractions. In 1973 the transmitted fraction is slightly underestimated. In this case the measured leaf-area index was as high as 5 , compared to 3.5 in 1972.
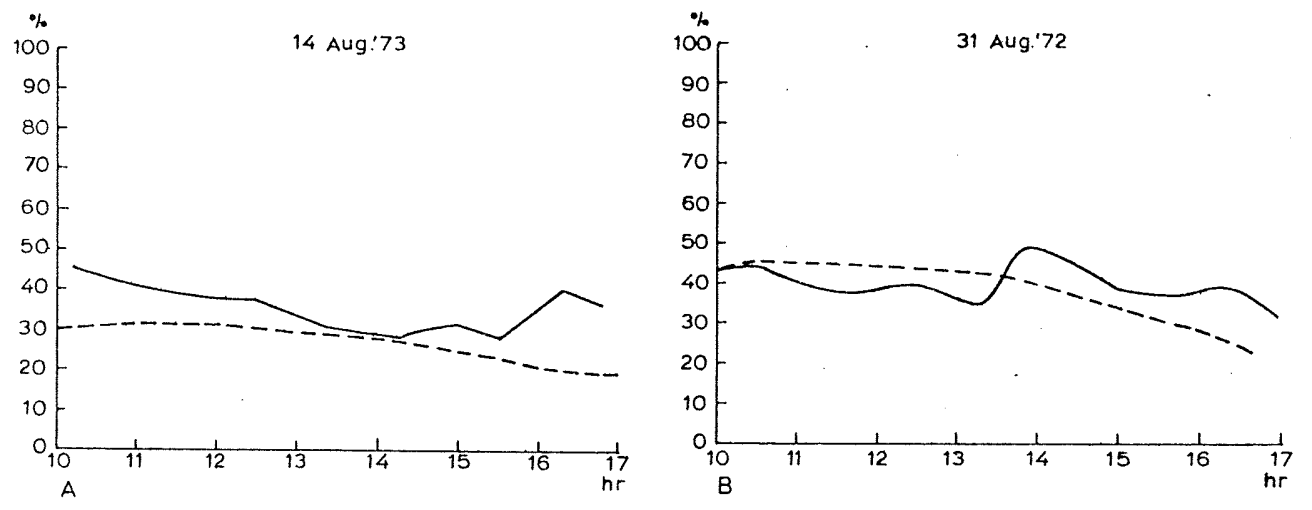

Fig. 4. Measured and simulated percentage transmission of net radiation at a height of $0.95 \mathrm{~m}$ on August 14, 1973 (A) and August 31, 1972 (B). - $=$ measured; -........ $=$ simulated.

\section{Wind profiles}

Simulated and measured wind profiles are given in Fig. 5 for all three measuring days. The agreement is as good as one could wish in view of the fact that the instruments measure omnidirectional air movement.

\section{Leaf conductivities}

The measured leaf resistances were reported by Stigter and Lammers (1974). One of their main conclusions is that sunlit leaf parts show little variation in leaf resistance. This is also indicated by the simulation, and is a consequence of saturation of the leaf photosynthesis-light response. In the range of sines of incidence angle of direct radiation from 0.4 to 1 , the simulated leaf resistance decreases only $20 \%$. The simulated differences with height in the canopy are negligible. In Fig.6 the simulated values for leaf conductivity for sunlit leaves are given for a sine of incidence angle of 0.35 , as a reasonable average of the sunlit leaves. The conductivities are given as a 


\section{4}
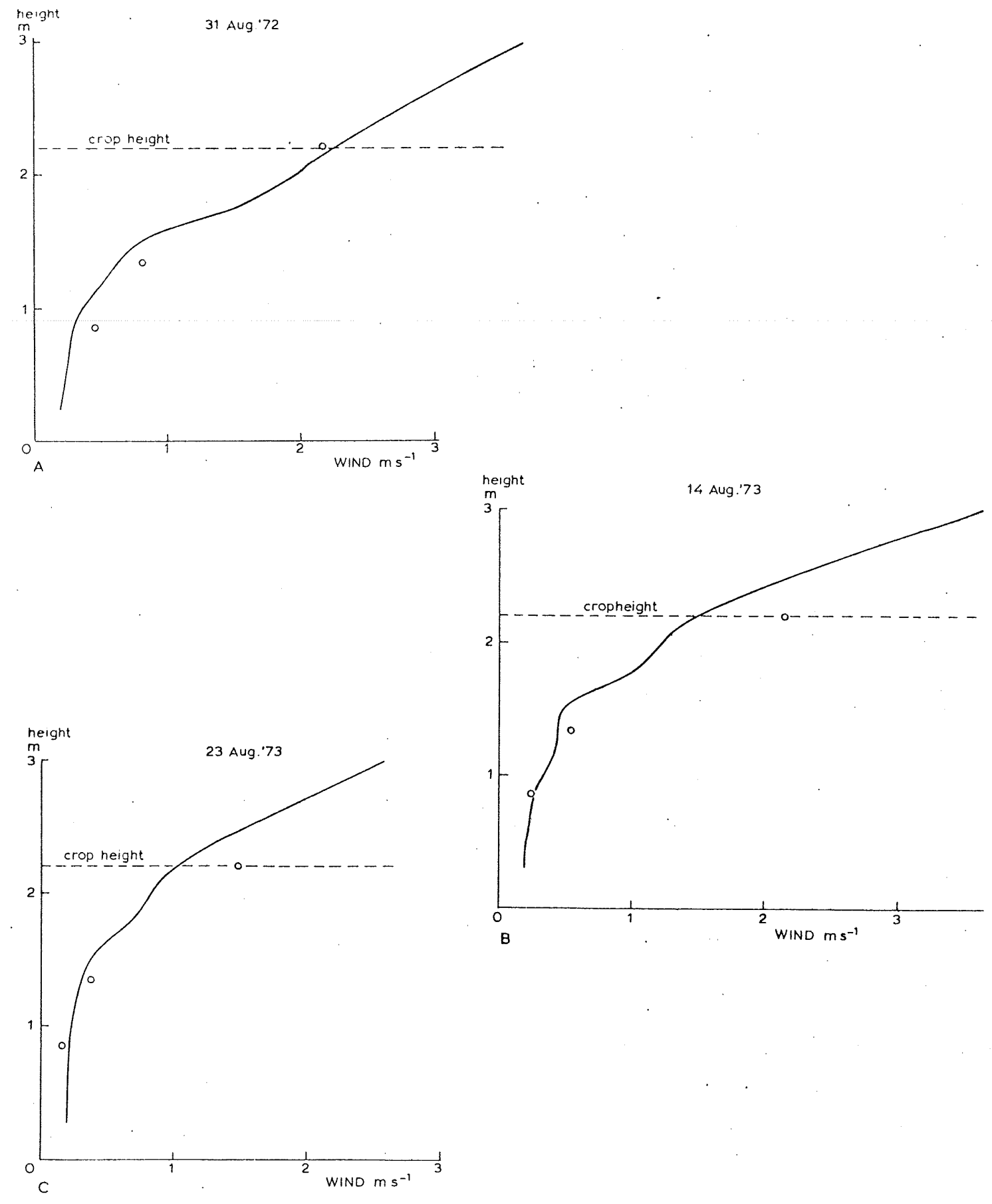

Fig.5. Measured and simulated windspeeds, averaged over the period 10h00-17h00, on August 31, 1972 (A), August 14, 1973 (B) and August 23, 1973 (C). - $=$ measured; $\mathrm{o}=$ simulated; -....... = crop height. 

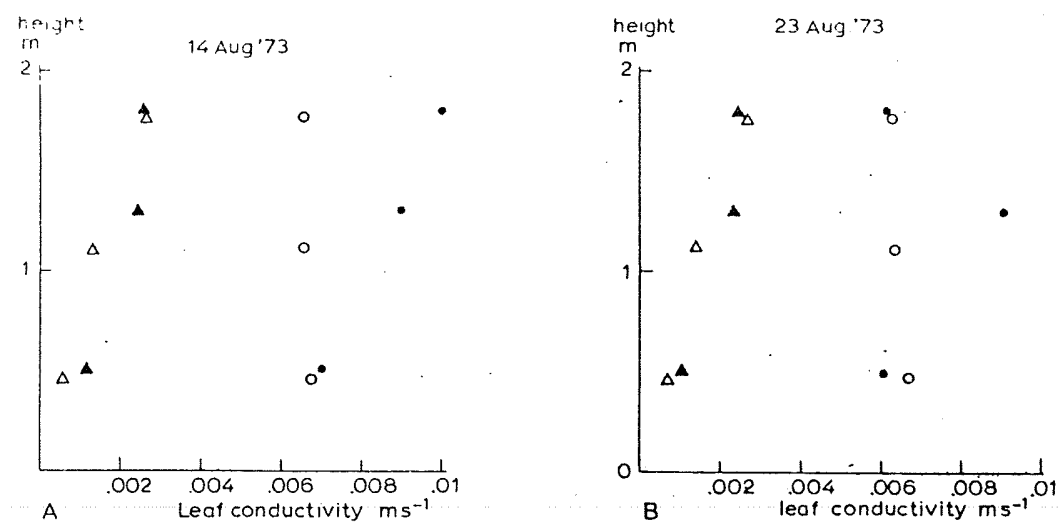

Fig.6. Measured and simulated leaf conductivities for water vapour, on August 14, 1973 (A) and August 23, 1973 (B). $\mathbf{\Delta}=$ measured, shaded; $=$ measured, sunlit; $\Delta=$ simulated, shaded; $O=$ simulated, sunlit.

sum of those for either side of the leaf. The shaded leaves exhibit a marked decrease of leaf conductivity with depth. Leaf conductivity is a better characteristic than leaf resistance, because the rate of transpiration is approximately proportional to conductivity. For the lowest layer the leaf conductivity is underestimated, so that the transpiration rate there will also be slightly underestimated. On the whole the simulated values agree quite well with the measured data. If data for sunlit leaf parts over four days are taken together, differences with height disappear. This indicates that the differences are due to the small size of the samples (Stigter and Lammers, 1974).

\section{Soil heat flux and soil temperature near the surface}

On August 31, 1972 and August 14, 1973 the soil surface was wet, whereas on August 23,1973 it was dry. Therefore the simulation was performed with a zero resistance for evaporation on the first two dates, and with a very high resistance on the latter. On the first two days the simulated soil temperature at $2 \mathrm{~cm}$ depth is too low, with a maximum difference of $3^{\circ} \mathrm{C}$ (Fig.7). It is likely that this was due to a too high evaporation rate, probably because later in the day the soil surface may have dried to some extent which was not taken into account in the simulation. This could also explain the phase shift in the simulated and measured soil heat fluxes (Fig.8). The maximum in the measured soil heat flux always occurred much later than in the simulated value.

However, the soil heat flux has also been calculated from measured temperature differences between 2 and $5 \mathrm{~cm}$ depth, and a constant conductivity for heat of $1.15 \mathrm{~J} \mathrm{~m}^{-1}{ }^{\circ} \mathrm{C}^{-1} \mathrm{~s}^{-1}$. These results are indicated by the open circles. It is remarkable that for these data the phase shift coincides 
176
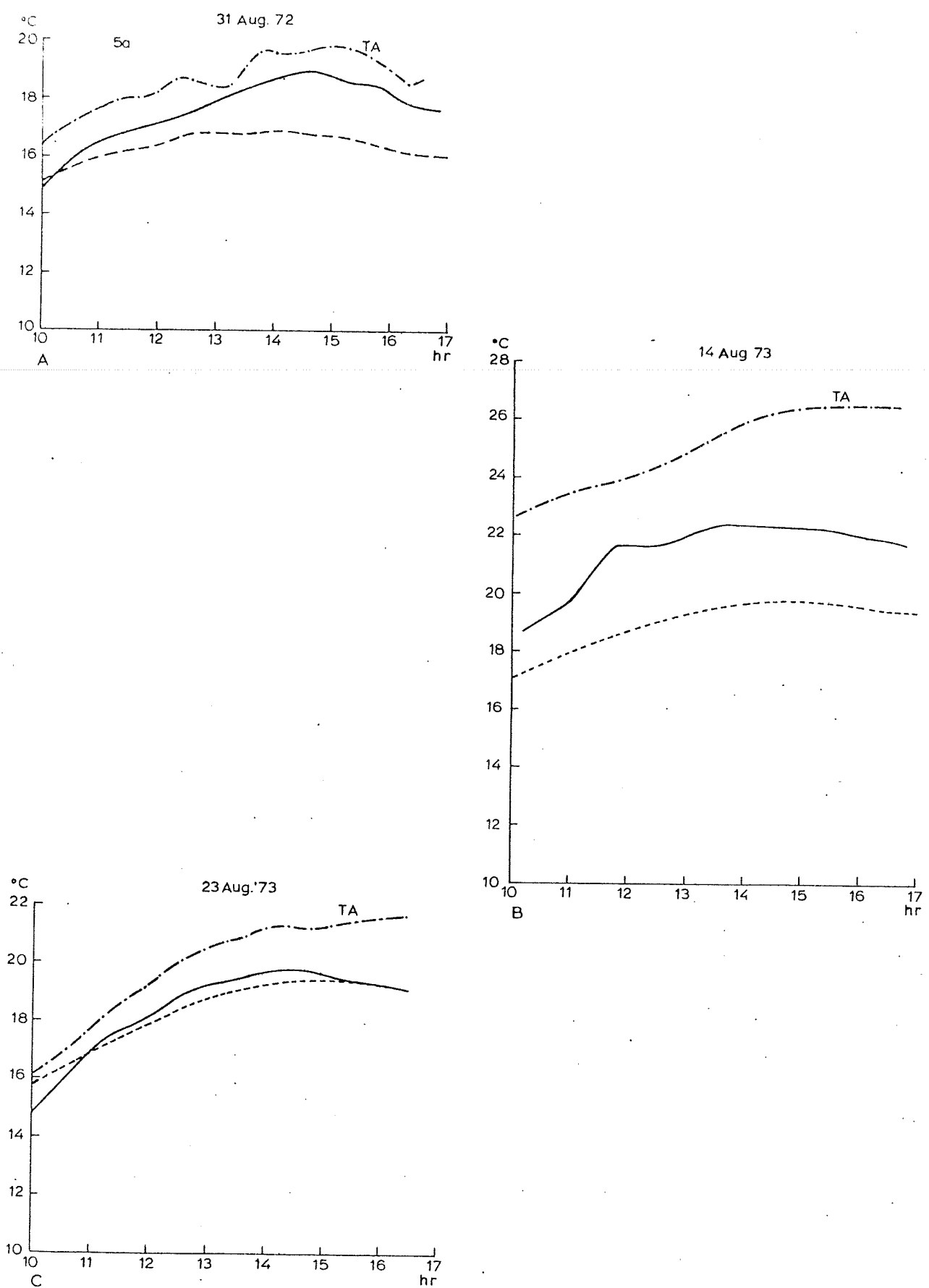

Fig. 7. Measured and simulated temperature in the soil at $2 \mathrm{~cm}$ depth on August 31, 1972 (A), August 14, 1973 (B) and August 23, 1973 (C).- = measured; simulated; $T A=$ measured air temperature at $3 \mathrm{~m}$ height. 

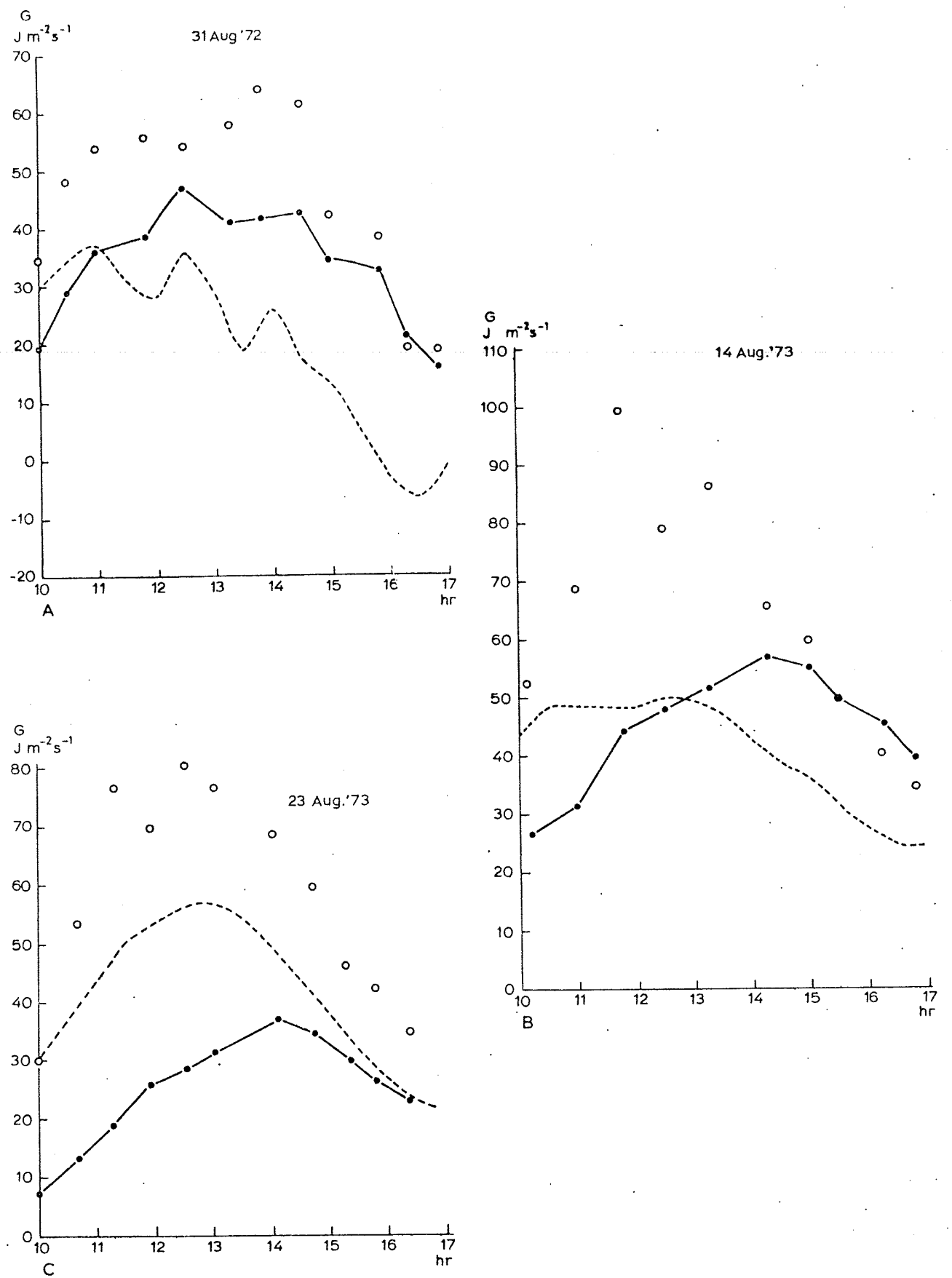

Fig.8. Measured and simulated soil heat fluxes at $2 \mathrm{~cm}$ depth on August 31, 1972 (A), August 14, 1973 (B) and August 23, 1973 (C).___ = flux measured by heat plates; $\mathrm{o}=$ flux, calculated from measured temperatures at 2 and $5 \mathrm{~cm}$ depth; simulated heat flux at $2 \mathrm{~cm}$ depth. 


\section{8}

better with the simulated values. It is possible that the heat flux plates inhibited an upward water movement, thereby creating a shallow dry soil layer above them.

\section{Profiles of air temperature and humidity}

In Fig.9 measured and simulated profiles of air temperature and humidity are given for 3 periods during the days August 31, 1972, August 14, 1973 and August 23, 1973. The deviations between measured and
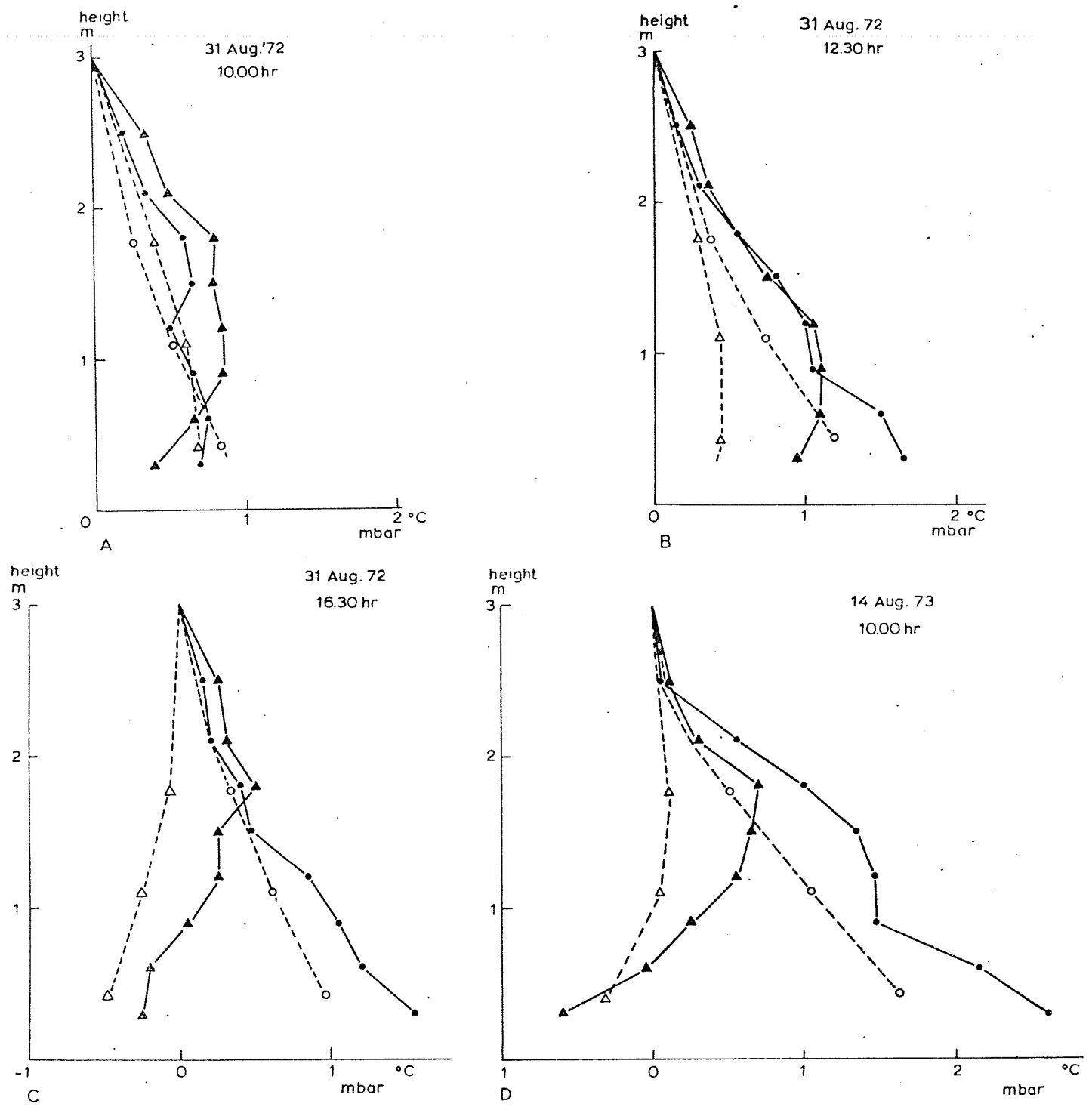

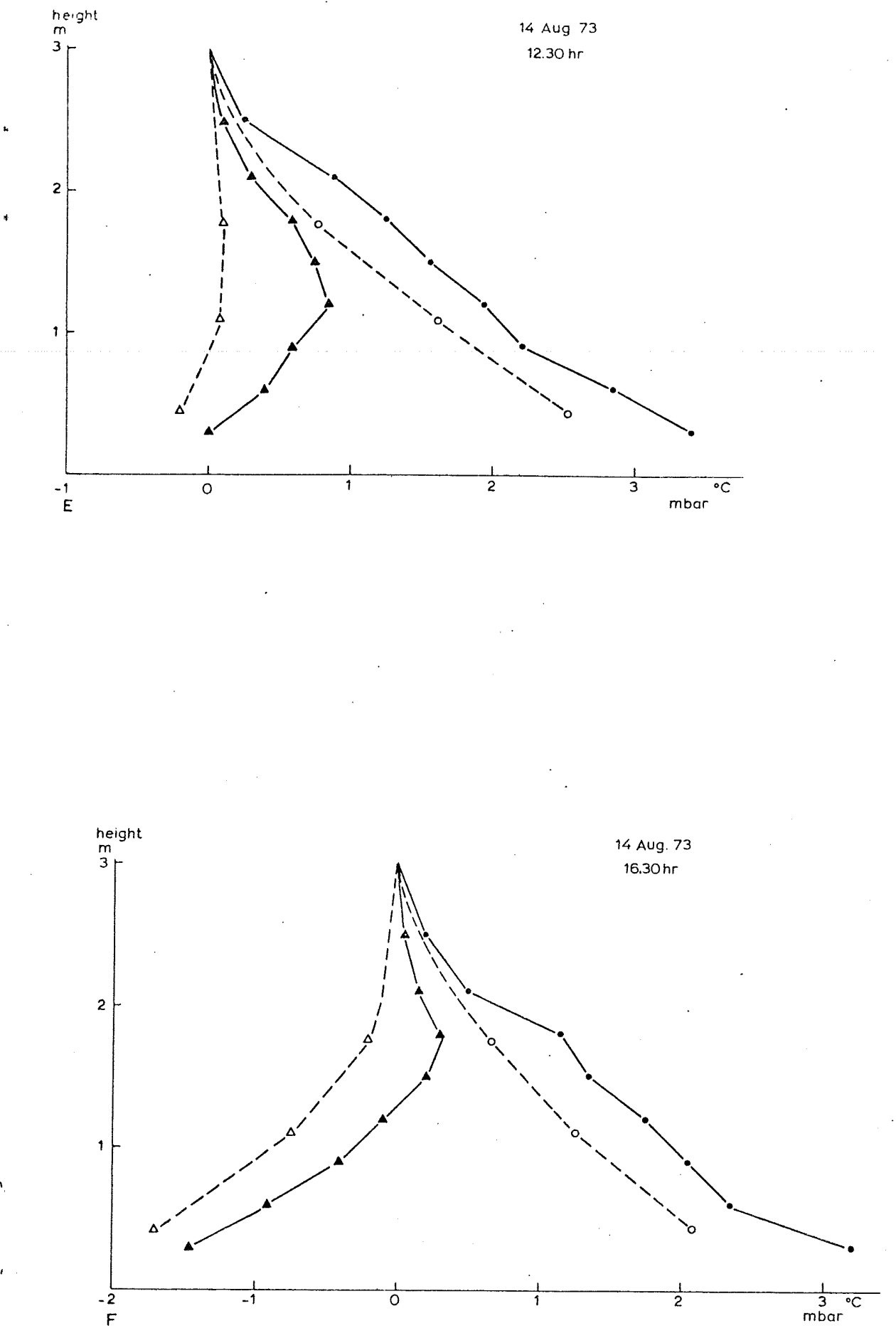

Fig.9. (Legend see p. 180.) 

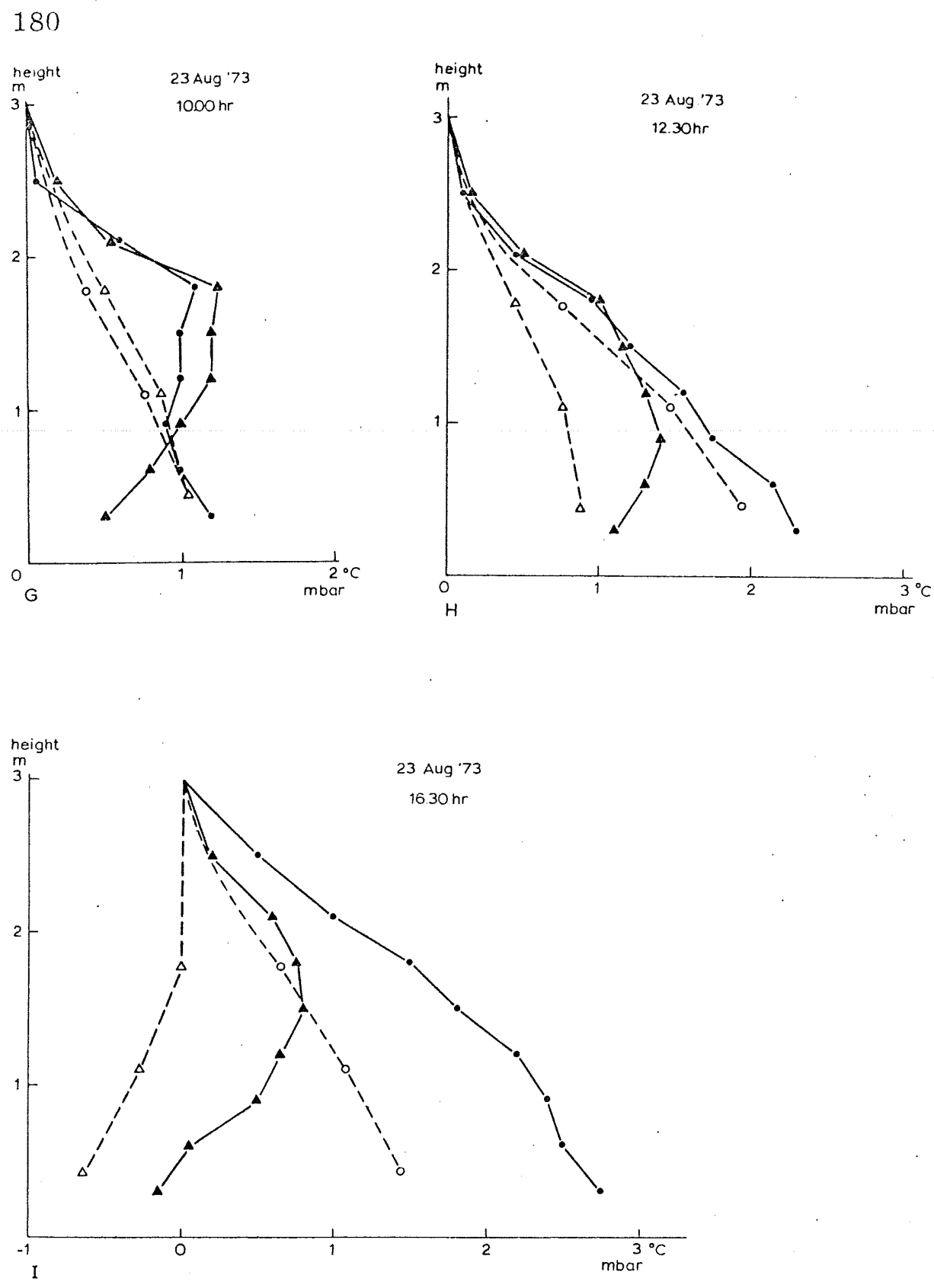

Fig.9. Measured and simulated profiles of air temperature and humidity on August 31, 1972 (A, B, C) August 14, 1973 (D, E, F) and August 23, 1973 (G, H, I), resp., for the moments $10 \mathrm{~h} 00,12 \mathrm{~h} 30$ and $16 \mathrm{~h} 30$.
measured
a simulated
$-1$
$\Delta-\cdots---\Delta$
air temperature $\left({ }^{\circ} \mathrm{C}\right)$
air humidity (mbar). 
simulated data are obvious, and have two characteristics in common:

(1) The simulated gradients are not steep enough, especially at about $2 \mathrm{~m}$ height, just under the top of the vegetation.

(2) The simulated temperature profiles do not show a maximum, which frequently occurs in the measured data between 0.5 and $2 \mathrm{~m}$ height.
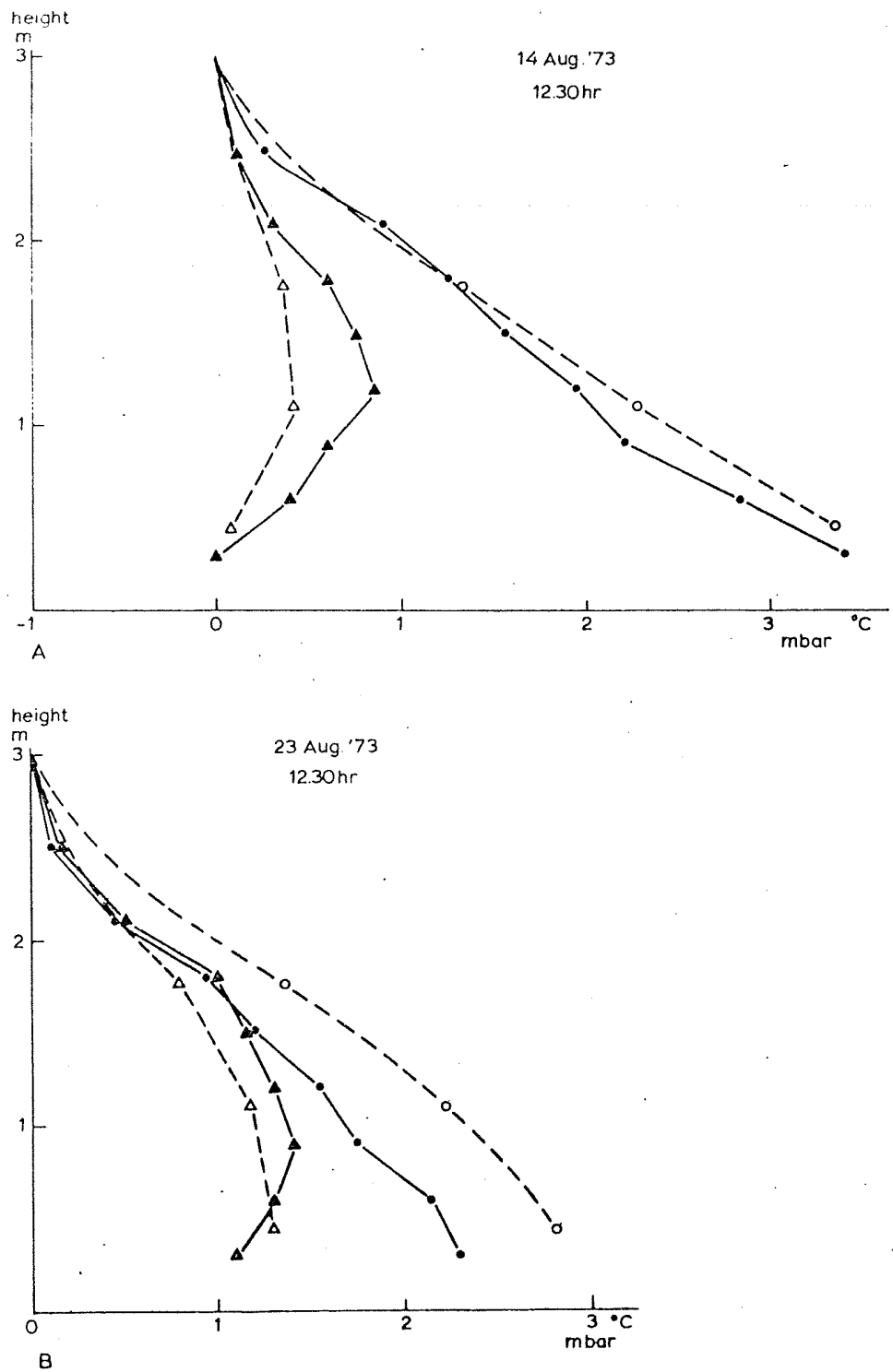

Fig.10. Simulated profiles of air temperature and humidity on August 14, 1973 (A) and August $23,1973(\mathrm{~B})$, both at $12 \mathrm{~h} 30$, obtained by reduction of the turbulence intensity (see text). 


\section{DISCUSSION OF THE RESULTS}

One of the aims of the simulation attempt is to indicate important gaps in our knowledge by tracing back the sources of deviations between simulation and measurement. The comparisons of radiation, wind profiles and leaf conductivities justify the conclusion that the radiation and leaf resistance submodels are sufficiently correct and do not cause the deviations. The simulation of the energy balance of the soil surface has probably some shortcomings, but since the energy fluxes at the soil surface do not exceed $20 \%$ of the total flux to be dissipated, errors in this submodel are not likely to cause deviations in the aerial profiles of the size observed; this was also confirmed in a sensitivity analysis (Goudriaan, 1977). The simulation of the exchange in the air remains as the possible source of the difficulties.

In this simulation the exchange coefficient was calculated as the product of wind velocity and mixing length, the relative vertical turbulence intensity implicitly taken as unity. Now the latter assumption is questionable,

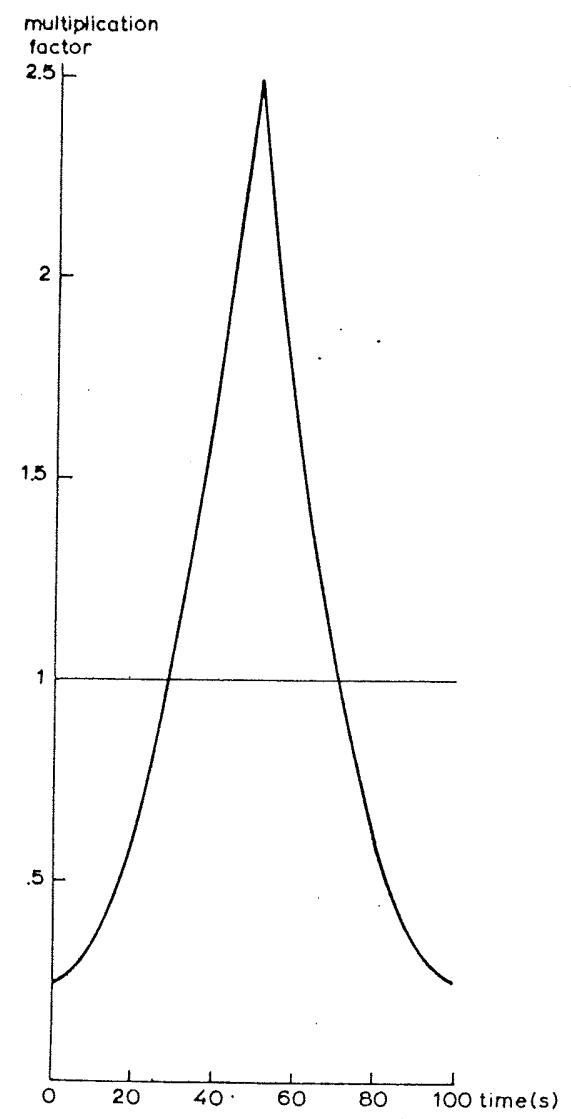

Fig.11. Multiplication factor for windspeed to represent gustiness, applied repetitively. 
especially near the top of the vegetation. Results of Shaw et al. (1974) show it to be less than unity, increasing from 0.3 near the top to 0.8 deeper down in the canopy. Application of this reduction factor results in profiles as given in Fig.10.

It seems also worth while to investigate the effect of temporal or spatial fluctuations of the exchange coefficient. Horizontal variations of the
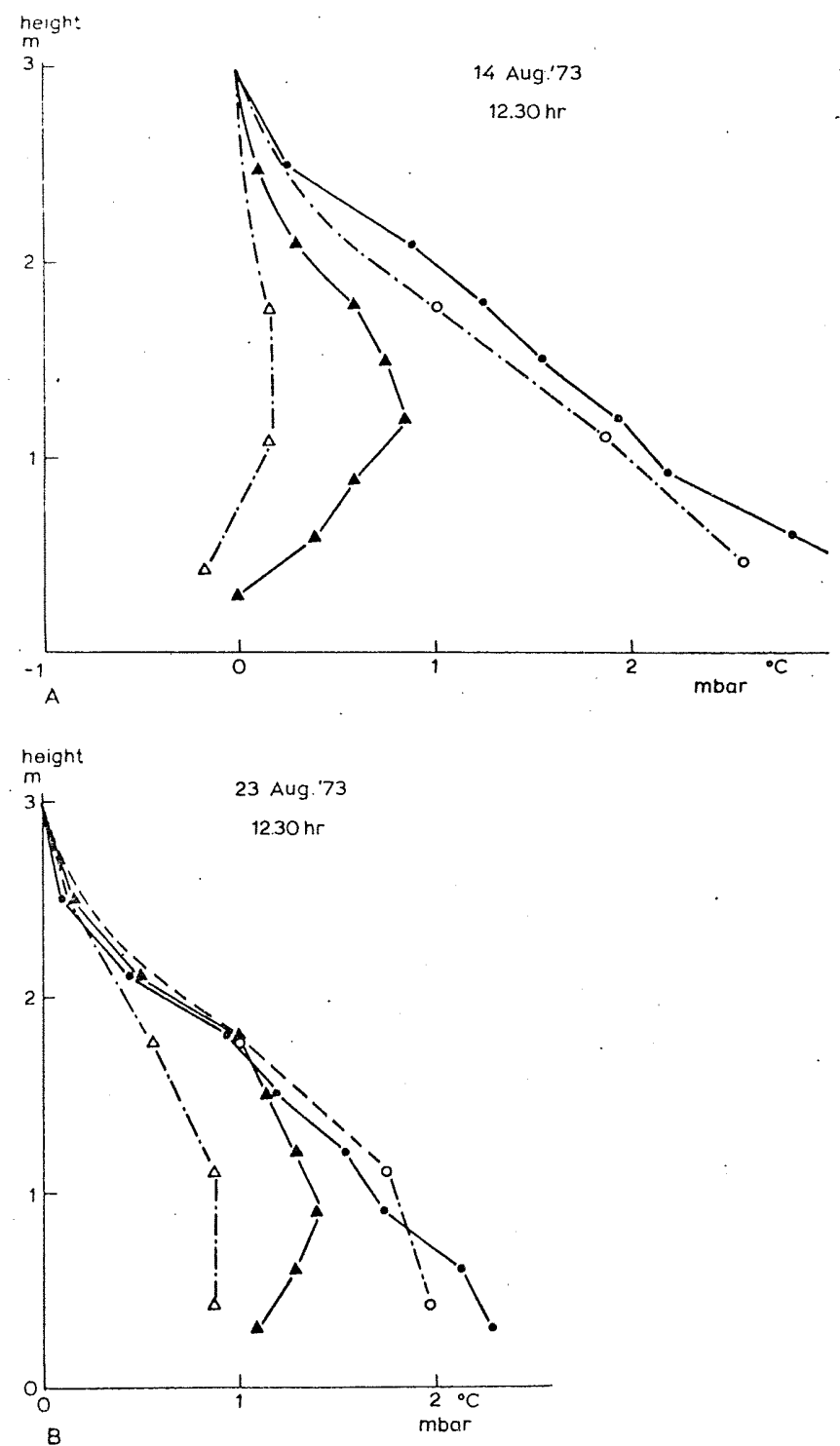

Fig.12. Simulated profiles of air temperature and humidity on August 14, 1973 (A) and August 23,1973 (B), both at $12 \mathrm{~h} 30$, obtained with a fluctuating windspeed according to Fig.11. 


\section{4}

exchange coefficient up to $50 \%$ of its mean value within distances of the order of $0.5 \mathrm{~m}$, which may be due to inhomogeneities in leaf-area density, appear to have a negligible effect on the shape of the horizontally averaged profiles. Temporary fluctuations in the exchange coefficient can originate from gustiness of the wind. The simulation results show that highly frequent changes in wind speed, above $1 \mathrm{~Hz}$, may be averaged since the heat and moisture content of the air cannot follow these fast changes. If on the other hand the frequency is lower than $0.001 \mathrm{~Hz}$, the windspeed may be considered as steady. In the frequency region $0.001-1 \mathrm{~Hz}$ the fluxes and driving forces are out of phase, and the average profiles of temperature and humidity change considerably. The gustiness of the wind was represented by a multiplication factor that varies periodically with time (Fig.11), and that has a mean value of unity, so that the total wind run remains equal. The simulated average profiles at $12 \mathrm{~h} 30$ are given in Fig. 12 .

In coimparison with a steady windspeed the gradients are increased, especially near the top of the canopy, so that the curves become more convex. Therefore, the maximum of the measured temperature profiles may be partly due to temporal fluctuations of the wind. It is likely that a more thorough interpretation of both the relative vertical turbulence intensity inside the canopy and the gustiness of the wind, will largely nullify the present differences between simulation and measurement. In so far as the physical knowledge of these phenomena is still lacking, it should be an item of priority in micrometeorological research.

\section{ACKNOWLEDGEMENT}

The authors acknowledge with great pleasure the skilful cooperation of the technical staffs of their departments in organization and performance of the many measurements involved.

\section{REFERENCES}

Bottemanne, F. A. and Reitsma, Tj., 1973. Windprofielmetingen boven Grasland; Windprofielmetingen boven Mais. Reports 73-1a and 73-1, Laboratory of Physics and Meteorology, Wageningen, $8+58 \mathrm{pp}$.

Businger, J. A., Wijngaard, J. C., Izumi, Y. and Bradley, E. F., 1971. Flux profile relationships in the atmospheric surface layer. J. Atm. Sci., 28:181-189.

Byrne, G. F., 1970. Data logging and scanning rate considerations in micrometeorological experiments, Agric. Meteorol., 7:415-418.

Byrne, G. F., 1972. Data logging and scanning rate considerations in micrometeorological experiments - a reply. Agric. Meteorol., 9:287-288.

Den Hartog, G. and Shaw, R. H., 1975. A field study of atmospheric exchange processes within a vegetative canopy. In: D. A. de Vries and N. H. Afgan (Editors), Heat and Mass Transfer in the Biosphere, I. Transfer Processes in Plant Environment. Scripta Book Company, Washington, D.C., pp. 299-310. 
De Wit, C. T. and Van Keulen, H., 1972. Simulation of Transport Processes in Soils. Pudoc, Wageningen, $159 \mathrm{pp}$.

Fuchs, M., 1972. Data logging and scanning rate considerations in micrometeorological experiments - a discussion. Agric. Meteorol., 9:285-286.

Gates, D. M., Keegan, H. J., Schleter, J. C. and Weitner, V. R., 1965. Spectral properties of plants. Appl. Opt., 4:11-20.

Goudriaan, J., 1977. Crop Micrometeorology: A Simulation Study. Pudoc, Wageningen, in press.

Goudriaan, J., and Waggoner, P. E., 1972. Simulating both aerial microclimate and soil temperature from observations above the foliar canopy. Neth. J. Agric. Sci., $20: 104-124$.

Goudriaan, J. and Van Laar, H. H., 1977. Measurement of some relations between leaf resistance, $\mathrm{CO}_{2}$-concentration and $\mathrm{CO}_{2}$-assimilation in maize, beans and sunflower. Submitted to Photosynthetica.

Kanemasu, E. T. (Editor), 1975. Measurement of Stomatal Aperture and Diffusive Resistance. Wash. State Univ., Coll. Agric. Res. Center Bull., 809, 38 pp.

Long, I. F., 1968. Instruments and techniques for measuring the microclimate of crops. In: R. M. Wadsworth (Editor), The Measurement of Environmental Factors in Terrestrial Ecology. Blackwell, Oxford, pp. 1-32.

Monteith, J. L., 1973. Principles of Environmental Physics. Edward Arnold, London, $241 \mathrm{pp}$.

Newman, J. E., 1974. Applying meteorology to agriculture. Agric. Meteorol., 13:1-3.

Pearman, G. I., Weaver, H. L. and Tanner, C. B., 1972. Boundary layer heat transfer coefficients. Agric. Meteorol., 10:83-92.

Ross, J., 1975. Radiative transfer in plant communities. In: J. L. Monteith (Editor), Vegetation and the Atmosphere, I. Principles. Academic Press, London, $278 \mathrm{pp}$.

Shaw, R. H., Den Hartog, G., King, K. M. and Thurtell, G. W., 1974. Measurements of mean windflow and three-dimensional turbulence intensity within a mature corn canopy. Agric. Meteorol., 13:419-425.

Stigter, C. J., 1972. Leaf diffusion resistance to water vapour and its direct measurement, I. Introduction and review concerning relevant factors and methods. Meded. Landbou whogesch. Wageningen, $72-3: 1-47$.

Stigter, C. J., 1974. The epidermal resistance to diffusion of water vapour: an improved measuring method and field results in Indian corn (Zea mays). Agric. Res. Rep., 831, Pudoc, Wageningen, $25 \mathrm{pp}$.

Stigter, C. J., 1975. Water vapour diffusion porometry for leaf epidermal resistance measurements in the field. In: D. A. de Vries and N. H. Afgan (Editors), Heat and Mass Transfer in the Biosphere, I. Transfer Processes in Plant Environment. Scripta Book Company, Washington, D.C., pp. 403-412.

Stigter, C. J., 1976. Water vapour pressure within a maize crop. Arch. Meteorol. Geophys. Bioklimatol., Ser. B, 24, in press.

Stigter, C. J., and Lammers, B., 1974. Leaf diffusion resistance to water vapour and its direct measurement, III. Results regarding the improved diffusion porometer in growth rooms and fields of Indian corn (Zea mays). Meded. Landbouwhogesch. Wageningen, 74-21: 1-76.

Stigter, C. J. and Visscher, G. J. W., 1975. Application of a new calibration method to an unventilated dynamic diffusion porometer. Neth. J. Agric. Sci., 23:303-307.

Stigter, C. J. and Welgraven, A. D., 1976. An improved radiation protected differential thermocouple psychrometer for crop environment. Arch. Meteorol. Geophys. Bioklimatol., Ser. B, 24:177-188.

Stigter, C. J., Birnie, J. and Lammers, B., 1973. Leaf diffusion resistance to water vapour and its direct measurement, II. Design, calibration and pertinent theory of an improved leaf diffusion resistance meter. Meded. Landbou whogesch. Wageningen, $73-15: 1-55$. 
186

Stigter, C. J., Lengkeek, J. G. and Kooijman, J., 1976a. A simple worst case analysis for estimation of correct scanning rate in a micrometeorological experiment. Neth. J. Agric. Sci., 24:3-16.

Stigter, C. J., Birnie, J. and Jansen, P., 1976b. Multi-point temperature measuring equipment for crop environment, with some results on horizontal' homogeneity in a maize crop, I. Field results. Neth. J. Agric. Sci., 24:223-237.

Van Keulen, H., 1975. Simulation of Water Use and Herbage Growth in Arid Regions. Pudoc, Wageningen, $176 \mathrm{pp}$.

Van Laar, H. H. and Penning de Vries, F. W. T., 1972. $\mathrm{CO}_{2}$-assimilation/light response curves of leaves, some experimental data. Verslagen I.B.S., 62, Wageningen, 53 pp.

Waggoner, P. E., Furnival, G. M. and Reifsnyder, W. E., 1969. Simulation of the microclimate in a forest. Forest Sci., 15:37-45. 